\title{
DUNE MIGRATION AND SAND TRANSPORT RATES IN TIDAL ESTUARIES: THE EXAMPLE OF THE RIVER ELBE
}

\author{
Anna Zorndt ${ }^{1}$, Andreas Wurpts and Torsten Schlurmann ${ }^{2}$ \\ Nino Ohle and Thomas Strotmann ${ }^{3}$
}

\begin{abstract}
Large parts of the tidal estuary of river Elbe (Germany) are characterized by regular patterns of sand dunes. They are presumed to evolve due to complex sand transport mechanisms and show multi-faceted migration patterns. Direction and magnitude of their migration are influenced by hydrodynamic boundary conditions such as river runoff and tides. Dune Migration can lead to residual sand transport rates, depending on its direction and magnitude and the dune's characteristics. The understanding of dune migration patterns and associated sand transport is the basis of an effective sediment management as well as an important requirement for planning offshore structures. This study focuses on methods for computing migration and sand transport rates in automated ways. In a comparison and validation of different approaches, a cross-correlation technique was found to produce best results. From a unique data set of up to six annual bathymetrical multi-beam soundings between 1995 and 2010, dune characteristics and migration rates were processed and analysed autonomously. The findings show that over the long run, average dune migration and sand transport rates in the present study reach are directed upstream.
\end{abstract}

Keywords: Sand Dunes, Dune Migration, Cross-Correlation Method, Sand Transport, Elbe Estuary

\section{INTRODUCTION}

Under special sedimentologic and hydrodynamic conditions (Zanke 1982), complex sediment movements on the river bed can lead to the formation of different sizes of bedforms. The same forcings which influence their formation can also cause a migration of bedforms, which results in residual sand transport, additionally to bed transport and transport in suspension. Many studies have been conducted to describe and characterize the forms (c.f. Führböter 1979; Dalrymple, Knight, and Lambiase 1978; Amos and King 1984) and to determine the influences of grain size, current velocity, water depth as well as form characteristics on the migration in both flume experiments and nature (c.f. Zanke 1982; Führböter 1967; Knaapen 2005).

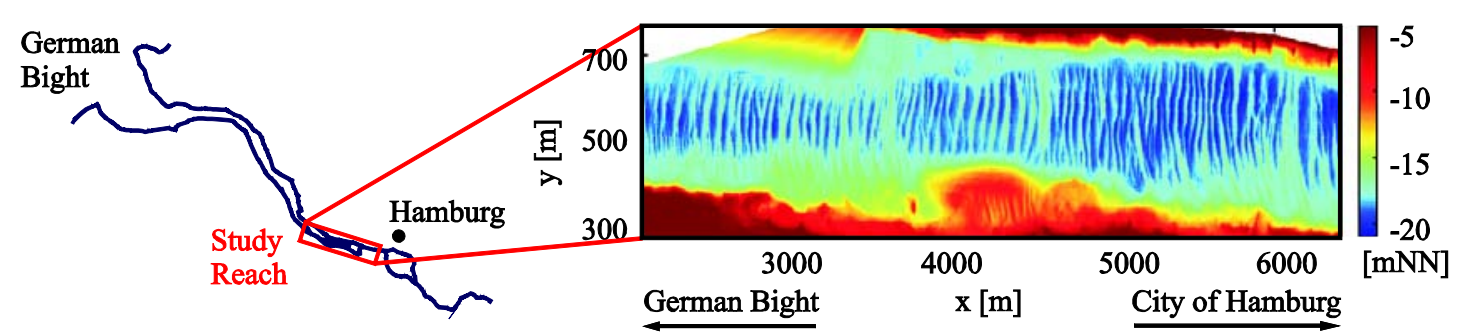

Figure 1. Study reach located in tidal river Elbe with detailed bathymetry (August 2008)

This study focuses on assessing dune migration rates and associated sand transport between the years 1995 and 2008 in a study reach in the Elbe Estuary (Germany). For this purpose, a set of methods to process and evaluate large data sets for dune migration and sand transport rates had to be developed and implemented.

\section{Study Reach and Data Basis}

The study reach is located approximately $100 \mathrm{~km}$ south-east of the Germany Bight close to Hamburg as shown in Figure 1. Despite the fact that the depicted area shows a superposition of bedforms of different sizes, this study focuses on investigating the primary bedforms with lengths of up to $100 \mathrm{~m}$, which will further on be referred to as sand dunes. As the formation of sand dunes is most pronounced in the deep navigation channel, the study focuses exclusively on this part of the river.

\footnotetext{
${ }^{1}$ Corresponding Author. E-Mail: zorndt@fi.uni-hannover.de, Phone: +49 5117622579

${ }^{2}$ Franzius-Institut for Hydraulic, Waterways and Coastal Engineering, Leibniz University Hannover. Nienburger Strasse 4, 30451 Hannover, Germany.

${ }^{3}$ Hamburg Port Authority, Neuer Wandrahm 4, 20457 Hamburg, Germany.
} 
The average tidal range in the study reach is $t r=3.40 \mathrm{~m}$. The mean water depth is $h=18 \mathrm{~m}$, while the average runoff from the inland river catchment mounts to $Q=700 \mathrm{~m}^{3} / \mathrm{s}$. The bathymetry of the area has been regularly measured for monitoring purposes by Hamburg Port Authority (HPA) by means of multi-beam echo-sounders with a frequency of $240 \mathrm{kHz}$. HPA provided a unique data basis of up to six soundings per year between 1995 and 2009 for this study, as well as bed samples and data from different gauges nearby.

\section{METHODS}

\section{Computation of Dune Characteristics}

It is common practice to describe dunes by means of features of their longitudinal sections shown in Figure 2. Many different ways of defining those parameters have been described (c.f. Gaeumann and Jacobson 2007; Mark and Blom 2007). Usually, a general distinction is made between features of the dune being on the stoss vs. on the lee side of the dune. This distinction is not suitable for this study, as dunes will be observed to change their shape over time, the stoss side usually being directed towards the German Bight but sometimes also facing Hamburg. Thus, instead of referring to stoss and lee side, there will be a distinction between features lying upstream from the crest of the dune and thus facing Hamburg, and features lying downstream, then being directed towards the German Bight (e. g. $h_{u s}$ vs. $\left.h_{d s}\right)$.

Here, dune height $h$ is defined as the average of upstream and downstream height, both being defined as the vertical distance between crest and upstream and downstream trough respectively. Dune length $L$ is defined as the horizontal distance between downstream and upstream trough. The asymmetry $A$ of the dunes is calculated as

$$
A=\left(L_{d s}-L_{u s}\right) / L,
$$

theoretically leading to values $-1<A<1$. Positive values correspond to a dune with its downstream slope being steeper than the upstream slope. Those dunes are also referred to as downstream orientated dune or dunes facing the German Bight.

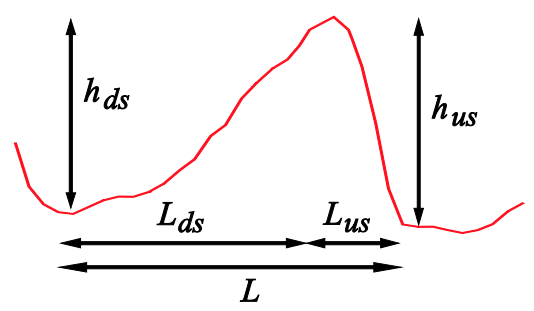

Figure 2: Sketch of dune characteristics

To assess the main dune characteristics, the horizontal and vertical positions of the dune's crest and troughs must be known. There are different approaches to find those positions in the longitudinal section.

(1.) When data sets and computational power used to be smaller, those positions were often chosen manually from a longitudinal section as shown in Figure 3 (e.g. Simons, Richardson and Nordin 1965). Here, this manual dune tracking approach was conducted only for exemplary data to calibrate and verify the results of an automated dune tracking as described below.

(2.) While there are different approaches for automated dune tracking as described by van der Mark and Blom (2007), the approach implemented in this study is based on finding the local minima and maxima in the longitudinal section and then deciding whether these are chosen as crest or trough on the basis of different criteria. Developing suitable criteria is crucial for the results especially in the case of composite dunes, which are compound of primary and secondary structures in contrast to dunes which have a regular shape (megaripples). Also, difficulties arise in case of dunes whose crests have been dredged for river maintenance. For the search algorithm, it is necessary to specify minimal dune heights and lengths for filtering depending on what kinds of bedforms should be in the focus of the study. Also, is has to be insured that the search algorithm is independent of the search direction. 
Here, minimal dune heights and lengths were found in an atomized calibration process. A range of minimal dune heights and lengths were combined and compared to the results of a manual dune tracking approach. For all combinations, the automated dune tracking algorithm was executed and from the results, dune characteristics were computed and averaged for each configuration. Those were then compared to dune characteristics assessed from the manual dune tracking method by means of comparing the averages but also by taking the results in the longitudinal sections visually into consideration. The criteria which produced the best correspondence to the manual dune tracking method were a minimal dune height and length of $h_{\min }=0.5 \mathrm{~m}$ and $L_{\min }=16 \mathrm{~m}$, respectively.

\section{Computation of Migration Rates}

A variety of methods to process and evaluate migration rates have been described in literature as reviewed by Bartholomä, Schrottke and Winter (2008).

(1.) In analogy to the dune characteristics, migration rates can be computed in a manual dune tracking (MDT) procedure as for example conducted by Nasner (1974). To derive migration vectors, two successive longitudinal sections of times $t_{i}$ and $t_{i+1}$ are compared visually and corresponding dunes with the same shape are matched manually as depicted in Figure 3. The migration rate $u$ is computed as the migration distance $\Delta x$ divided by the time interval $\Delta t=t_{i+1}-t_{i}$ between the soundings. The migration vector is defined as the distance between the positions of the same dune in two successive longitudinal sections. This position of the dune can be defined in different ways, i.a. as (i) the crest of the dune, (ii) the average between the two troughs of the dune and (iii) the average of the three positions of the two troughs and the crest. The latter definition produced the least variance over one longitudinal section and can thus be interpreted as the best definition of a relatively stable position of a dune.

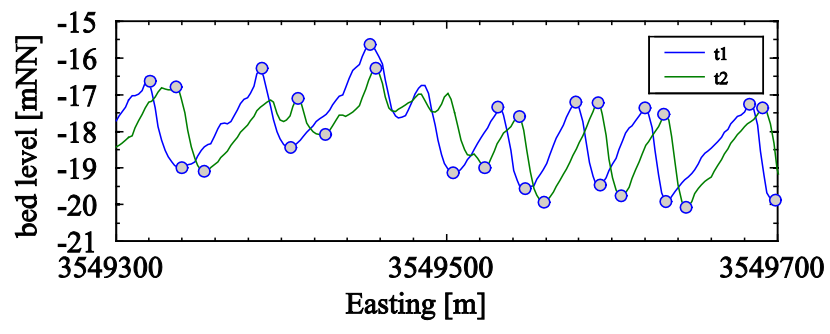

Figure 3: Manual dune tracking

This manual approach was conducted for exemplary data. Despite the inherited subjectivity when it comes to superimposed structures or bathymetries altered by dredging, it is the most exact approach, as the researcher will discard areas where no similarity between the dunes can be seen. While the timeconsuming manual work for this approach forbids the application to large data sets as given in this study, it is very well suited for calibrating and verifying results of automated approaches. In this contribution, two automated approaches to compute migration rates were implemented and compared to the results derived from the manual dune tracking.

(2.) A mathematical approach to calculate dune migration rates (Milbradt, Sellerhoff and Krönert 2004) was implemented. This method approximates the degree of change for every point in the bathymetry based on local gradients in time and 2D space. In this paper, it will be referred to as the local gradient method (LGM).

The aim of the method is to compute the migration vector $\Delta X$ in two dimensions for any point in the bathymetry as shown in Figure 4 (left) in one dimension. As it is not possible to determine $\Delta X$, it is expanded with $\Delta z$ so that the migration rate $V$ can be approximated as

$$
V=\frac{\Delta X}{\Delta t}=\left(\frac{\Delta z}{\Delta X}\right)^{-1} \cdot \frac{\Delta z}{\Delta t},
$$

where the local gradients $\Delta z / \Delta X$ and $\Delta z / \Delta t$ can be calculated.

In this study, the gradient in space $\Delta z / \Delta X$ is implemented as 


$$
\left(\frac{\Delta z}{\Delta X}\right)_{n, i, i+1}=\left\{\left\{\begin{array}{l}
\left(z_{n+1}-z_{n-1}\right) \\
\left(x_{n+1}-x_{n-1}\right) \\
\frac{\left(z_{n+1}-z_{n-1}\right)}{\left(y_{n+1}-y_{n-1}\right)}
\end{array}\right\}_{i}+\left\{\begin{array}{l}
\frac{\left(z_{n+1}-z_{n-1}\right)}{\left(x_{n+1}-x_{n-1}\right)} \\
\frac{\left(z_{n+1}-z_{n-1}\right)}{\left(y_{n+1}-y_{n-1}\right)}
\end{array}\right\}_{i+1}\right) \cdot 0.5
$$

for any point $X_{n}$ in two successive soundings at times $t_{i}$ and $t_{i+1}$ which is illustrated in Figure 4 (right) for 1D. The local time gradient $\Delta z / \Delta t$ is implemented as

$$
\frac{\Delta z_{n, i, i+1}}{\Delta t_{i, i+1}}=\frac{z_{n, i}-z_{n, i+1}}{t_{i+1}-t_{i}},
$$
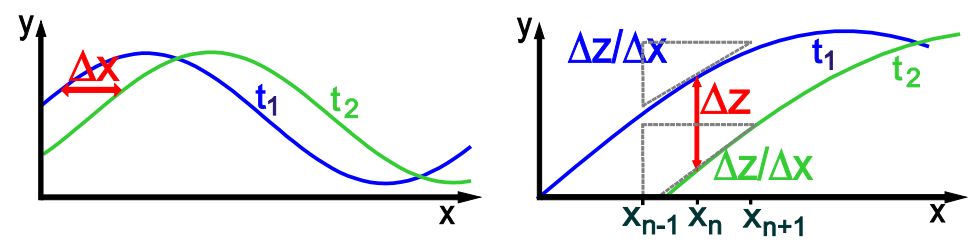

Figure 4: Local gradient approach, left: migration distance to be computed; right: approximation

On crests and in troughs of the dunes, the difference in height $\Delta \mathrm{z}_{n}=\mathrm{z}_{\mathrm{n}+1}-\mathrm{z}_{\mathrm{n}-1}$ is often close to zero so that the outcome must be multiplied with a smoothing function

$$
\frac{\Delta X}{\Delta t}=\left(\frac{\Delta z}{\Delta X}\right)^{-1} \cdot \frac{\Delta z}{\Delta t} \cdot \max \left(0,1-\frac{\sqrt{\varepsilon}-|\Delta z / \Delta X|}{\sqrt{\varepsilon}-\varepsilon}\right)
$$

where $\varepsilon$ is the smoothing factor. A parameter study to find a suitable smoothing factor was conducted for 1D. While smoothing factor $\varepsilon=0$ shows strong outliers as expected, $\varepsilon=0.005$ leads to a good smoothing for high values and plausible values for the intervals between crests and troughs.

(3.) The cross-correlation method (CCM) is a statistical method which was first described and applied to dune migration by (Duffy and Hughes-Clarke 2005) and relies on finding the best statistical match of a section in a $2 \mathrm{D}$ bathymetry given at time $t_{i}$ with any section of the successive bathymetry at time $t_{i+1}$. From the distance of those best-matching sections, migration vectors and thus rates can be derived.

The equation for a normalized cross-correlation matrix is

$$
q_{b}=(1-\varepsilon) \cdot \frac{A}{\lambda} \cdot \frac{\Delta x}{\Delta t}
$$

which results in a matrix with $u \times v$ values, each presenting the correlation coefficient $R$ between the bathymetry at time $t_{i}$, called $f$ at position $x, y$, and the successive bathymetry at time $t_{i+1}$ called $g$, which is shifted $u$ steps in $x$-direction and $v$ steps in $y$-direction. The highest correlation $R_{\max }$ in this matrix can in most cases be interpreted as the position to which the structure in section $f$ has migrated (limitations see below). This can be calculated for every position of the bathymetry (except for the boundary areas), but was only calculated every $8 \mathrm{~m}$ to decrease computation time.

For applying this method, an appropriate size for the sections $f$ and $g$ has to be determined. Section $f$ has to be large enough to represent enough characteristic features of the bathymetry at time $t_{i}$ so that they can be recognized in the successive one. Section $g$ in the successive bathymetry at time $t_{i+1}$ on the other hand, has to be chosen sufficiently large so that the migrated structure still lies within it. In a parameter study, different combinations for the width $w$ and length $l$ of $f$ in the range of $12 \mathrm{~m} \leq w \leq 60 \mathrm{~m}$ resp. $20 \mathrm{~m} \leq l \leq 80 \mathrm{~m}$ were compared. Section $\mathrm{g}$ was enlarged to be four times the size of $f$. The decision was based primarily on comparing maximal values of $R$ and on visual inspection of the plausibility of the resulting field of migration vectors. The sizes producing best results were found for $w=20 \mathrm{~m}$ resp. $l=40 \mathrm{~m}$. 
The limitation of this method lies in the fact that the dunes have a regular shape so that successive dunes are often quite similar. Hence, there can be mismatches with preceding or successive dunes. This is especially the case when dredging activities have altered the bathymetries or when the time interval $\Delta t$ between the two soundings is too long. Because of that, the quality of the results relies much on filters, which remove outliers but at the same time ensure keeping the correct vectors.

For this purpose, different filters similar to those known from particle image velocimetry (PIV), can be applied to the results. To begin with, global filters erase migration vectors that are not within a certain range specified by the user, while global statistic filters devalue values that are not within a certain range around a mean value, the range being specified by means of a variance and a factor. Furthermore, local filters remove values in analogy, but are based on criteria specified only for a local area. In a parameter study, all of those filters turned out to be problematic, as they only devaluated few outliers and many correct values. The limitations of statistic filters lie in their dependence on a variance which can locally be in different orders of magnitude, the non-statistic ones rely too much on the subjectivity in the choice of parameters.
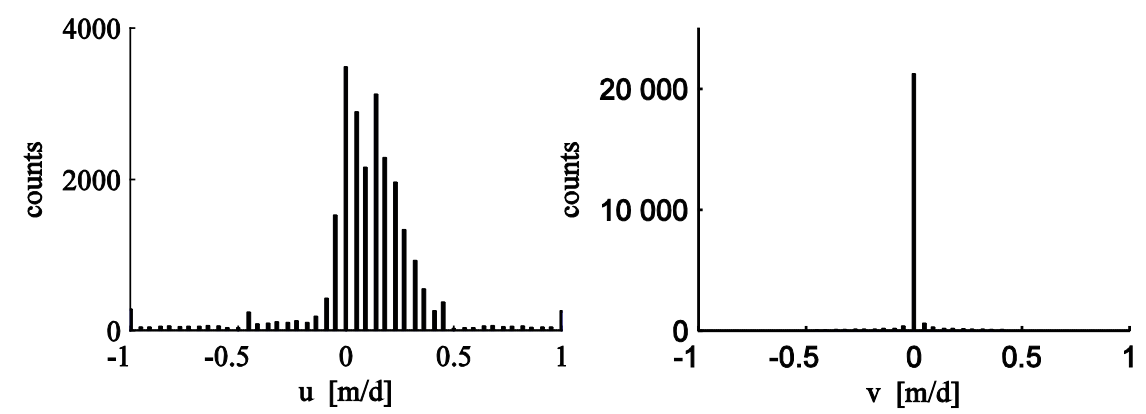

Figure 5: Example of histogram filter

Instead, a global histogram-filter was implemented. In the course of the filtering procedure, a figure is presented, showing a histogram of the migration vector field between two successive soundings. As presented in Figure 5, the results generally seem to agree with a somewhat Gaussian distribution around a mean value, the counts smoothly decreasing on both lobes of the distribution. However, a certain grade of bimodality can be observed so that these migration vectors can be interpreted as outliers. The user gets suggestions for a range of values that will be accepted as correct migration vectors, which are computed by means of gradients in the distribution. Nevertheless, he yields the opportunity to change the range based on his own estimation of the ends of the distribution, ensuring the quality of the range chosen to remove these values. To ensure a certain degree of quality resemblance in terms of the correlation coefficient, after this procedure, values with a correlation coefficient of $R \leq 0.9$ were also discarded.

(4.) The results of the two methods described above were in a first step compared to each other in 2D. In a second step, they were verified by means of comparison to the results of a manual dune tracking in 1D.

For the comparison of the CCM and the LGM, the migration vector fields of both solutions for one exemplary calculation from mid-2008 were interpolated on the same grid. For every applied method, the average migration rates in both directions $u$ in $x$ - and $v$ in $y$-direction were calculated, as well as the average norm $U$ and its angle $\alpha$. Moreover, the difference between the two solutions for every point of the grid was calculated.

\begin{tabular}{|c|c|c|c|c|}
\hline & $u[\mathrm{~m} / \mathrm{d}]$ & $v[\mathrm{~m} / \mathrm{d}]$ & $U[\mathrm{~m} / \mathrm{d}]$ & $\alpha\left[^{\circ}\right]$ \\
\hline CCM & 0.1020 & 0.0008 & 0.1335 & 9.7313 \\
\hline LGM & 0.0461 & -0.0035 & 0.1101 & -2.1490 \\
\hline DIFF & 0.1008 & 0.0794 & 0.0869 & 80.2732 \\
\hline
\end{tabular}


The results shown in Table 1 illustrate that the average of the local difference between both methods (DIFF) is rather large compared to the migration rates determined by the cross-correlation (CC) and local gradient (LGM) methods. This effect is strongly pronounced for the velocity component $v$, which also results in very high values for the direction of the angle $\alpha$. This can be explained by the fact that the $y$-direction of the results of the LGM depends mainly on the direction of the main gradient of the slope. Hence, the resulting migration vector is mostly perpendicular to the crest of the dune, an effect which in all probability reflects the underlying physics. This is not the case for the CCM, where the $y$-direction is determined by the position of the highest correlation coefficient between two sections. The method generally producing superior results for the migration direction $v$ cannot be verified in this study. This local difference also exists for the results of the migration rate $u$, though not as high as for $v$.

\begin{tabular}{|c|c|c|c|}
\hline \multicolumn{4}{|c|}{ Table 2. Comparison of cross-correlation method and local } \\
gradient method to manual dune tracking \\
\hline & CCM & LGM & MDT \\
\hline$u[\mathrm{~m} / \mathrm{d}]$ along longitudinal & 0.149 & 0.099 & 0.15 \\
\hline
\end{tabular}

The results of the migration rate $u$ in $x$-direction can be verified by means of comparison to results of manual dune tracking (MDT). For this purpose, an average migration rate $u$ of both methods CCM and LGM was computed only along the same longitudinal section to which the MDT was applied. The numbers in Table 2 show that the CCM reproduces the MDT results almost exactly, while the LGM underestimates the migration rates significantly by about one third. Thus, it can be concluded that the CCM is better suited for calculating migration rates in this study; hence, all results presented in the next sections have been computed applying the cross-correlation approach. As the results in $y$-direction cannot be verified by all means, the results will not be analyzed any further.

(5.) A qualitative approach to estimate migration rates is to visualize the morphologic tendency of the area as shown in Figure 6.

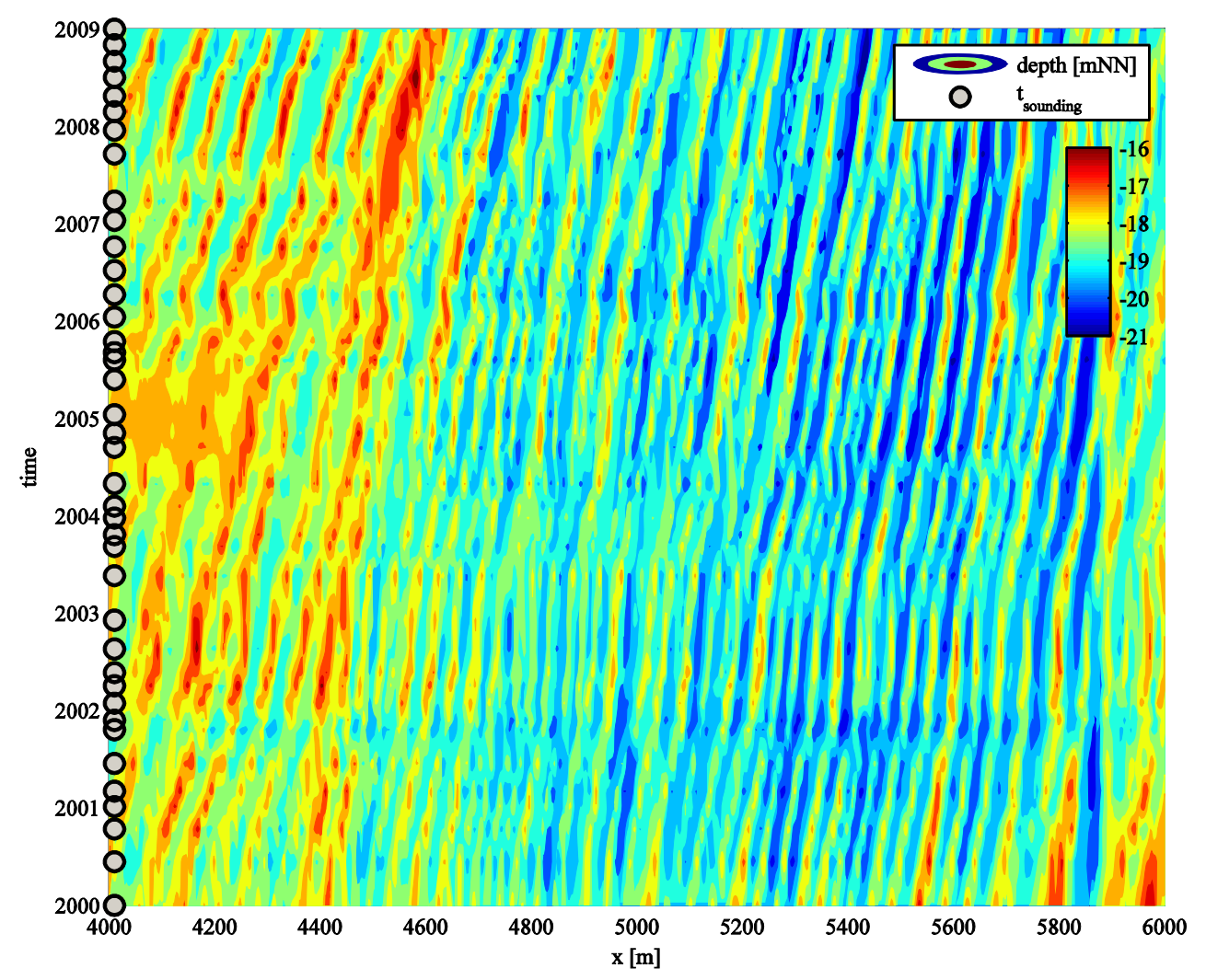

Figure 6: Morphologic tendency of a longitudinal section in the middle of the navigation channel between 2000 and 2009, grey dots indicating the measuring times of the bathymetries 
This is conducted by plotting longitudinal sections of the same position at different times above one another and interpolating the depths, crests of the dunes being shown in red, the troughs in blue. Here, this was conducted for the same longitudinal sections which were also analyzed with MDT, for the time between 2000 and 2009. The grey dots on the vertical axis indicate the instances when bathymetric data was collected.

The interpolation between the longitudinal sections reveals an almost constant eastward-directed migration the crests and troughs of the dunes. To give a very rough estimate from a quick look analysis, the plot shows a migration of about $100 \mathrm{~m}$ in the course of one year in areas of strong migration. This would indicate a migration rate of up to $u=0.27 \mathrm{~m} / \mathrm{d}$.

While this method can not quantify migration rates exactly, it can give only rough estimates of what is to be expected. Furthermore, large-scale trends and changes in migration rates can be detected.

\section{Estimation of Associated Sand Transport Rates}

For computing the associated sand transport $q_{b}$ in $1 \mathrm{D}$, conventional dune tracking studies usually apply a principle following the equation

$$
q_{b}=(1-\varepsilon) \cdot \frac{A}{L} \cdot \frac{\Delta x}{\Delta t}
$$

with the soil porosity $\varepsilon$, migration distance $\Delta x$ and time interval $\Delta t$ (Simons, Richardson and Nordin 1965; Gaeumann and Jacobson 2007). The dune's slice plane $A$ and length $L$ are calculated for the same dune at times $t_{i}$ and $t_{i+1}$ and then averaged. In this study, this approach was applied to the findings of the manual dune tracking approach which was conducted for an exemplary set of data (see above).

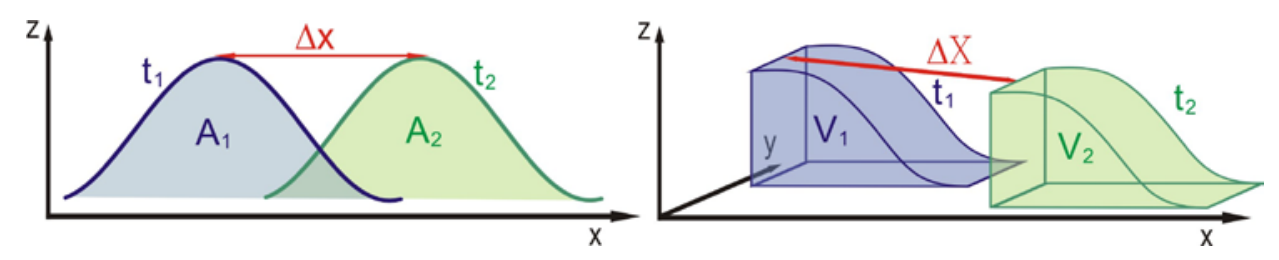

Figure 7: Computation of transport rates in 1 vs. 2 dimensions

To compute sand transport in an automated way, this $1 \mathrm{D}$ approach is expanded to estimate 2Dtransport rates of an arbitrary volume $V$, which is assumed to be the quantity above a horizontal basis level $B$ as illustrated in Figure 7. This leads to equation

$$
\bar{q}_{b}=(1-\varepsilon) \cdot \frac{V}{B} \cdot \frac{\Delta X}{\Delta t}
$$

which can then be applied to the results of the cross-correlation method. For verification, the results were compared to those of manual dune tracking: Applying Equation 7 to results of MDT for two successive soundings in mid 2008 leads to a sand transport rate of $q_{b}=0.1327 \mathrm{~m}^{3} / \mathrm{dm}$ per day and meter, while the application of Equation 8 to the CCM results show a sand transport rate of $q_{b}=0.1324 \mathrm{~m}^{3} / \mathrm{dm}$ in $x$-direction, both without taking a soil porosity into account. It can be concluded that despite the fact that the computed sand transport rates rely on the average dune height defined by volume $\mathrm{V}$ and base level $\mathrm{B}$, the approach gives reasonable results for this parameterisation of the CCM.

\section{RESULTS}

\section{Dune Characteristics}

To compute dune characteristics for all of the 58 soundings between 1995 and 2009, the automated dune tracking approach described above was applied to a longitudinal section in the middle of the navigation channel, perpendicular to the dune crests.

Figure 8 shows the results for one representative sounding in mid 2008. The average dune height is $h=1.94 \mathrm{~m}$, the average length $L=55.18 \mathrm{~m}$. The dunes are characterised by a clear asymmetry with $a=0.28 \mathrm{~m}$. 

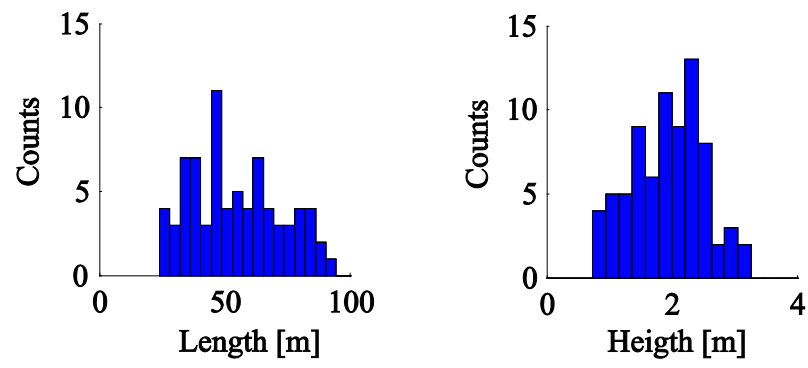

Figure 8: Dune characteristics computed with automated dune tracking approach for mid 2008

Taking into account all soundings, the dunes in the longitudinal section have heights of $1.23 \mathrm{~m} \leq h \leq 1.98 \mathrm{~m}$ with an average of $h=1.70 \mathrm{~m}$ and lengths of $13.27 \mathrm{~m} \leq L \leq 61.62 \mathrm{~m}$ with an average of $L=46.47 \mathrm{~m}$. The computed asymmetries range between $-0.189 \leq a \leq 0.305$, showing an average of $a=0.14$. In the average over the whole study period, a share of $72.7 \%$ the dunes were orientated upstream.

\section{Migration Rates}

The findings shown in this section have been computed with the cross-correlation method. Only the results in the deep navigation channel are shown and taken into account for computing averages.

Figure 8 shows the filtered results for the migration rate $u$ in $x$-direction computed for one representative pair of soundings end 2008 with a time interval of $\Delta t \leq 61 \mathrm{~d}$. While there are areas with high rates of up to $u=0.3 \mathrm{~m} / \mathrm{d}$, some regions in the south of the navigation channel show even small negative migration rates. This effect can partly be explained by the fact that this area has regularly been used as a deposition area for dredged material, so that depths are shallower (see Figure 1). Also, it has been observed that in this specific reach of the river, flood currents tend to be deflected to the north, while ebb currents tend to concentrate more on the south side of the channel, due to specific geometric features of the nearby bathymetry.

Over the whole area in total, there was an average migration rate of $u=0.1113 \mathrm{~m} / \mathrm{d}$ in the direction of Hamburg as shown in Figure 9.

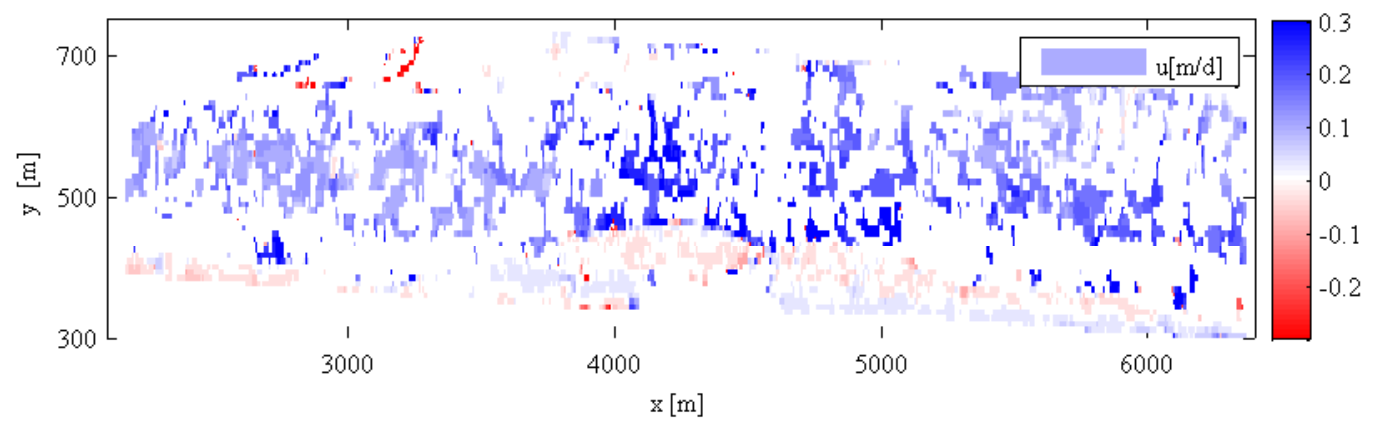

Figure 9: Dune migration computed with cross-correlation approach for mid 2008

Taking into account all soundings between 1995 and 2009, migration rates range between $-0.14 \mathrm{~m} / \mathrm{d} \leq u \leq 0.27 \mathrm{~m} / \mathrm{d}$ with an average $u=0.07 \mathrm{~m} / \mathrm{d}$ in the direction of Hamburg

\section{Sand Transport Rates}

Sand transport rates presented in this section were computed by applying Equation 8 to the results of the cross-correlation method.

For the representative pair of soundings from mid 2008, the average sand transport rate in the direction of Hamburg is $q_{b}=0.108 \mathrm{~m}^{3} / \mathrm{dm}$, without taking a porosity of the sand into account. During the whole study period, sand transport rates varied between $-0.15 \mathrm{~m}^{3} / \mathrm{dm} \leq q_{b} \leq 0.25 \mathrm{~m}^{3} / \mathrm{dm}$, showing an 
average of $q_{b}=0.073 \mathrm{~m}^{3} / \mathrm{dm}$. The area of the deep navigation channel, which was considered for the average values, has an average width of $w=278 \mathrm{~m}$, so that the sand transport can be calculated to $q_{b}=20.298 \mathrm{~m}^{3} / \mathrm{d}$ for the whole navigation channel width.

Based on this, it can be roughly estimated that in this study reach, there has been an average sand transport caused only be dune migration of approximately $q_{b}=7000 \mathrm{~m}^{3} / \mathrm{a}$ per year between 1995 and 2009.

\section{Influence of river runoff on migration rates}

The average migration rates computed in this study for every successive pair of soundings have a range of about $\Delta u=0.4 \mathrm{~m} / \mathrm{d}$. This variety can mainly be explained by the predominating effects of the prevailing runoff in river Elbe. For every successive pair of soundings at $t_{i}$, and $t_{i+1}$, migration rates were computed and the corresponding runoff measured at a nearby gauging station was averaged. The plot shows all pairs with a time interval of less than $\Delta t=90 \mathrm{~d}$. While during times of average river runoffs around $Q_{i, i+1}=7000 \mathrm{~m}^{3} / \mathrm{d}$, migration rates were directed towards Hamburg, the migration direction changes for higher runoffs.

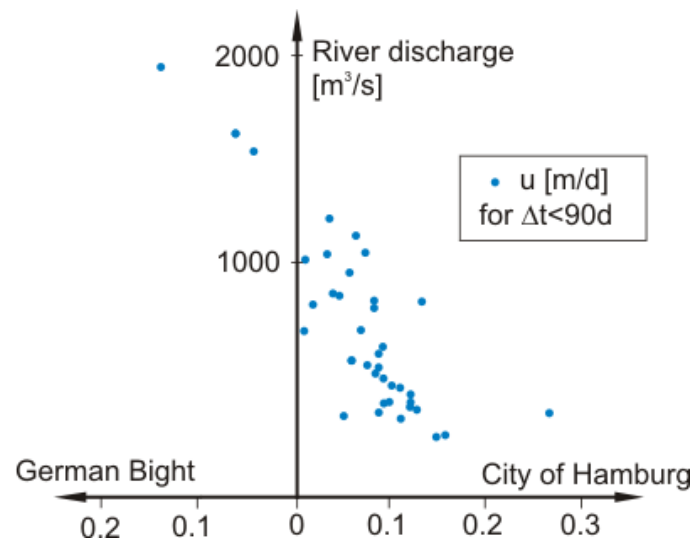

Figure 10: River runoff and migration rate

\section{CONCLUSIONS AND DISCUSSION}

The aim of this paper was to account for dune migration rates and associated sand transport in a study reach in the Elbe Estuary on the basis of a data set of 58 bathymetries measured between 1995 and 2009. To analyze the data set in an automated way, different methods have been implemented, tested and compared.

For computing dune characteristics, an automated dune tracking algorithm was implemented. Dunes showed average characteristics of $h=1.70 \mathrm{~m}, L=46 \mathrm{~m}$ and a strong asymmetry of $a=0.14$. This already indicates a dune migration directed towards Hamburg, as dunes are known to migrate towards their steeper slope (Knaapen 2005). Based on this, the dunes found in the present study reach can be best characterized as megaripples type 1 according to the definition of Dalrymple et al. (1978), although also some multi-crested composite structures can be found.

In order to compute migration rates, two different approaches were applied and subsequently, performances and accuracies were compared to each other. The cross-correlation approach turned out to be best applicable to the given data and could be verified by comparison to results of a manual dune tracking approach. Averaged over the whole study period, migration was directed towards Hamburg with an average rate of $u=0.07 \mathrm{~m} / \mathrm{d}$. Rate and direction of the migration were strongly related to river runoff, low and average runoffs resulting in an upstream migration, high runoffs causing a reversal of migration direction. The fact that the migration is directed upstream mimics the significant effect of tidal straining in the estuary, i. e. flood-induced currents and triggered bed sheer stresses show larger magnitudes than during ebb tide. A further study on the influence of hydrodynamic and other boundary conditions on migration as well as characteristics of the dunes is currently conducted.

Based on the migration rates computed in study, the associated sand transport was estimated to be around $q_{b}=7000 \mathrm{~m}^{3} / \mathrm{a}$. As this resembles only as a marginal quantity in relation to to the amount of sediments which is dredged in Hamburg every year for maintaining the navigation channel depths, it can be concluded that sand transport in dunes in the depicted river reach does not play a relevant role in this regime. Nevertheless, there are other transport mechanisms that are not taken into account here 
which might lead to a transport of material directed towards Hamburg, such as transport in suspension or bed-load transport. Also, the study is limited on examination regarding large-scale movements of primary bedforms and smaller superimposed structures are not analysed. Nonetheless, some recent studies indicate that sand transport calculated by dune migration can account for bed-load transport over the dunes because of the fact that the latter is in the same order of magnitude than transport in bedforms (Villard and Church 2003; Masselink et al. 2009; Gaeumann and Jacobson 2007). However, the fact that the residual migration is directed towards Hamburg illustrates the strong effect of tidal straining in this fluvial regime and points out that this effect plays a strong role in the sediment dynamics of the river Elbe.

\section{REFERENCES}

Amos, C. L. and E. L. King. 1984. Bedforms of the Canadian Eastern Seabord: A comparison with global occurances. Marine Geology 57: 167-208.

Bartholomä, A., K. Schrottke and C. Winter. 2008. Sand Wave Dynamics- Surfing between assumptions and facts. Marine and River Dynamics: 17-24.

Dalrymple, R. W, R. J Knight and J. J Lambiase. 1978. Bedforms and their hydraulic stability relationships in a tidal environment, Bay of Fundy, Canada. Nature 275 (5676): 100-104.

Duffy, Garret P. and John E. Hughes-Clarke. 2005. Application of spatial cross correlation to detection of migration of submarine sand dunes. Journal of Geophysical Research 110: F04S12.

Führböter, A. 1967. Zur Mechanik der Strömungsriffel. Mitteilungen des Franzius-Instituts für Wasserbau und Küsteningenieurwesen der Technischen Universität Hannover 29.

Führböter, A. 1979. Strombänke (Grossriffel) und Dünen als Stabilisierungsformen. Mitteilungen des Leichtweiss-Instituts der Technischen Universität Braunschweig 67.

Gaeumann, D., and R. B Jacobson. 2007. Field Assessment of Alternative Bed-Load Transport Estimators. Journal of Hydraulic Engineering: 1319-1328.

Knaapen, M. A. F. 2005. Sandwave migration predictor based on shape. Journal of Geophysical Research 110: FS0411.

Mark, C. F. Van der and A. Blom. 2007. A new and widely applicable tool for determining the geometric properties of bedforms. University of Twente.

Masselink, Gerd, Laurie Cointre, Jon Williams, Roland Gehrels and Will Blake. 2009. Tide-driven dune migration and sediment transport on an intertidal shoal in a shallow estuary in Devon, UK. Marine Geology 262: 82-95.

Milbradt, P., F. Sellerhoff and N. Krönert. 2004. KoDiBa Abschlussbericht - Entwicklung und Implementierung von Methoden zur Aufbereitung konsistenter digitaler Bathymetrien. imtg.bauinf.uni-hannover.de KFKI Signatur: E 35237.

Nasner, Horst. 1974. Über das Verhalten von Transportkörpern im Tidegebiet. Mitteilungen des Franzius-Instituts für Wasserbau und Küsteningenieurwesen der Technischen Universität Hannover 40: 1-149.

Simons, D. B, E. V Richardson and C. F Nordin. 1965. Bedload equations for ripples and dunes. U. S. Geol. Surv. Prof. Pap. 462-H.

Villard, P.V. and M. Church. 2003. Dunes and associated sand transport in a tidally influenced sandbed channel: Fraser River, British Columbia. Can. J. Earth. Sci. 40 (September): 115-130.

Zanke, Ulrich. 1982. Grundlagen der Sedimentbewegung. Springer-Verlag. 